\title{
Grammar and culture in the work of Yamuna Kachru
}

\author{
DANIEL R. DAVIS*
}

\begin{abstract}
This paper examines Professor Yamuna Kachru's construction of grammar in the context of work that adopted a number of different approaches to linguistics, each with its proper data, methodology, and theoretical concerns. These approaches are the standard theory of generative grammar, relational grammar, and grammar from the perspectives of discourse analysis, sociolinguistics, and systemic functional (Hallidayan) linguistics. Throughout her research and publications on grammar and culture, Professor Kachru's work challenges and extends traditional linguistics in a creative and innovative fashion, providing a unique contribution to our understanding of Hindi and English, and to that of grammar and of culture.
\end{abstract}

\section{INTRODUCTION}

Yamuna Kachru's published linguistic research spans five decades, during a time in which linguistics experienced extensive growth and intensive redefinition. Her work is shaped by the development of the field, by the marketplace for linguistic ideas and forms, and ultimately by her changing interests, but retains impressive cohesion as a body of knowledge. Pivotal to this cohesion and central to the work is Yamuna Kachru's changing conception of grammar. This paper examines Kachru's construction of grammar in the context of work that adopted a number of different approaches to linguistics, each with its proper data, methodology, and theoretical concerns. These approaches are the standard theory of generative grammar (Chomsky 1957, 1965), relational grammar, and grammar from the perspectives of discourse analysis, sociolinguistics, and Firthian/Hallidayan linguistics. Also relevant to Kachru's construction of grammar in her work are the formal and stylistic requirements of descriptive grammar. The term 'approach' is used loosely here, to cover different theoretical frameworks, different levels of linguistic analysis, and different branches or sub-fields of linguistics. Publication and research on each of these different aspects of linguistics nevertheless makes explicit assumptions about key components of language and linguistic research, including theoretical concepts, method, and data. The way that a scholar sets about work within linguistics is what gives the term 'approach' its validity.

\section{GENERATIVE GRAMMAR}

Yamuna Kachru's first work as a scholar focuses on the syntax of Hindi, using a generative grammar approach, defining grammar thus:

*Department of Language, Culture, and Communication, University of Michigan-Dearborn, Dearborn, MI 481282406, USA. E-mail: davisdr@umich.edu 
A language is a set of sentences, and a grammar is a set of rules that specify the sentences of a language. The notion rule is not to be understood in the sense of prescriptive or non-prescriptive, but rather in the sense of what organization of elements is allowed by a particular language to form sentences in that language. (Kachru 1966: 27).

In its emphasis on description, organization, and how sentences are formed (or generated), this account is fundamentally similar to that given in Chomsky $(1957: 13,106)$, 'From now on I will consider a language to be a set (finite or infinite) of sentences and constructed out of a finite set of elements.' Both quotations focus on syntax and are cautious about meaning, in keeping with Chomsky (1957: 106), 'Grammar is best formulated as a selfcontained study independent of semantics.' The account is an approximation of human linguistic competence:

What the grammar does is as follows: it gives (1) a list of the elements of a language, (2) rules about how to juxtapose them, and (3) specifications of operations that are performed on organized parts or sentences, which are labeled, to generate new organized parts or more complex sentences. It thus provides a better approximation to the nature or human linguistic competence suggested by the creative aspect of linguistic activity. (Kachru 1966: 16)

This idea of a grammar as an empirical description of the linguistic competence underlying language behavior remains consistent in Yamuna Kachru's work. She situates her discussion of Hindi syntax in the context of traditional, historical, and structural grammars of Hindi, and adopts generative theory and methodology because of its demonstrable superiority in giving an account of the data produced by speakers of the language. As she states, 'the application of the transformational model to the study of Hindi has resulted in deeper insight into the working of the Hindi grammar.' (Kachru 1966: 1).

Kachru's publications from 1966 to 1974 demonstrate the utility of generative grammar when applied to Hindi syntax. For example, Kachru (1970a) makes the argument that the variable postpositions used in the possessive construction in Hindi need not be described with reference to English grammar (as earlier accounts tended to do) and that, with modifications, the rules provided by generative grammar can describe the possessive in Hindi, commenting that:

The question arises: Is the apparatus of the inherent features of nouns provided by the theory of transformational grammars capable of specifying the features mentioned above? The answer is yes, if the CS and the transformational rules are supplemented by 'spelling rules' (Kachru 1970a: 42).

The 'spelling rules' are here proposed by Kachru as another form of lexical substitution rule, which spell out the postposition required after the application of possessive and relative transformations. The relevant postpositions have possessive as well as locational uses, but only the possessive uses allow a particular surface form. In addition, the choice of postposition is determined by the lexical/semantic features of the noun possessed.

The examples used in this analysis are Hindi, with translation. As is the case with both generative and structural descriptive grammars, they are presented as the plausible output of speakers of the language under study, depending on the intuition of the linguist as speaker. Kachru's original introductory data set in this paper contains nine different examples of noun phrases containing a possessive noun phrase marked with a form of 
the genitive postposition $k a$, paired with the corresponding possessive sentence. Three of these nine are reproduced here:

(1) $\mathrm{ram}$ ki betī

Ram post daughter

'Ram's daughter'

(2) ram ke ek beți $\mathrm{h} \varepsilon$

Ram post det daughter $\mathrm{BE}$

'Ram has a daughter'

(3) ləṛkke kī kitab

boy post book

'The boy's book'

(4) lorkke ke pas ek kitab he

boy post det book BE

'The boy has a book'

(5) kəmre ka dərvaza

room post door

'The door of the room'

(6) kəmre mẽ darvaza $\mathrm{h} \varepsilon$

room post door $\mathrm{BE}$

'The room has a door' (Kachru 1970a: 37-38)

It is noticeable that, as may be seen above, Kachru does not present starred (or unacceptable) examples in this particular analysis. This calls to mind structuralist practice, which relies on positive rather than negative data, and also suggests a line of interpretation that, as a multilingual speaker of Hindi, Kachru subscribes to the principle that the linguist's intuition should extend to supplying data that are possible in the language analyzed, rather than supplying data that are presumed not to be possible in the language analyzed. But examples marked unacceptable do appear in Kachru (1966: 110), precisely in connection with postpositions and the possessive.

Kachru (1973c) analyses the process of pronominalization in Hindi, and considers whether relative clause construction relies on pronominalization or Equi-NP deletion. By means of 102 examples, she demonstrates that only forward pronominalization occurs in Hindi, and makes the argument that, rather than adopting an inconsistent and expensive backward pronominalization rule to account for data on relative clauses, it would be more elegant and economical to hypothesize a deletion rule that is required elsewhere in the grammar of Hindi. The discussion is characterized by empiricism, a focus on description rather than theory, and a sense of using the advantages that the model affords in order to provide an elegant and economic characterization of the language examined. There are two further points in this paper that are worthy of note in light of the later development of Kachru's research. First, although most of the examples are unsourced and presumed to be spoken examples of 'Modern Standard Hindi/Urdu,' one data set is derived from newspapers and is explicitly noted as such. 
The sentences given here have been taken from written sources (Saptahik Hindustan of June 25, 1972 and Dharmyug of September 10,1972). But, such phrases are equally appropriate in spoken Hindi-Urdu. (Kachru 1973c: 95, 101 fn 14)

Second, examples from the Dakhini variety of Hindi are used to illustrate a particular output of the process of relative clause reduction, namely, that it is possible to delete the relative marker independently of the correlative marker (Kachru 1973c: 97, $101 \mathrm{fn}$ 18; citing data from Schmidt 1969). In both of these cases, varietal data constitutes a key part of the evidence for a particular analysis of the mainstream spoken variety.

In the mid-1970s, often publishing with her graduate students, Kachru expanded from her Aspects-era generative approach to include reference to Relational Grammar. This can be seen in Kachru et al. (1976e), which evaluates the status of the functional or relational category 'subject' in Hindi, Punjabi, and Kashmiri. This study finds that, in these languages, neither semantic properties, such as semantic roles, nor morphological properties, such as verbal agreement or case marking, nor even syntactic properties, such as functioning as the controller of syntactic processes, provide a clear delineation of the category. Rather, a hierarchy of subjecthood can be developed indicating which subjects (intransitive, transitive, dative, oblique, and passive) in these languages are able to control the syntactic processes of Reflexivization, Equi, Raising, and Conjunction Reduction. This result raises difficulties for Relational Grammar, because 'if relational categories are not discrete, what then does it mean to treat them as primitives in the theory of relational grammar?' (Kachru et al.1976e: 79).

In these treatments, we see an initial preference for a highly structured and theorized Aspects model gradually yield to the pressure of theory-internal problems and theoryexternal language data. Generative grammar at first provides a methodology to analyze properties of Hindi syntax in term of the language as a system in its own right, without resting on a point-by-point contrast with the syntax of English. Gradually, the cracks begin to show, as the explanation of grammatical relations provided by phrase structure rules cannot adequately account for observable features in Hindi. The Relational Grammar critique of Aspects-model grammar is taken up, but then found to be in itself problematic as an account of the linguistic phenomena of languages of South Asia. The data in question are by and large a product of a generative approach. They depend on the linguist's introspection, on constructed examples, and on acceptability judgments. Nevertheless, gradually, data from dialects and print sources are introduced. The 'Standard' language of the idealized speaker-hearer is no longer sufficiently empirical. This empiricism is then pursued in Kachru's second line of research, in the area of pragmatics.

\section{PRAGMATICS}

Kachru (1975b) anticipates the importance of pragmatics in her later work. In a discussion of the role of contrastive analysis in language learning and teaching, Kachru addresses the problem of identifying equivalence between different languages, with reference to recent work in the area (Fillmore 1965; Ferguson 1968; Catford 1968; Krzeszowski 1971). Identifying equivalence between languages, and thus contrasting their respective grammars, should in theory be possible by reference to a universal base for human languages, pending the successful identification of such a base. But this project had not (and some would argue, has not even now) borne fruit. 
This failure to characterize what is meant by equivalence is no doubt partly due to the lack of a viable linguistic theory. To the extent that no linguistic theory has yet been successful in characterizing a universal base for human languages, contrastive analysis cannot refer to this to characterize equivalences between languages. (Kachru 1975b: 4)

Citing Krzeszowski (1971), Kachru traces the implications of the observation that congruence of structure between different languages is relatively rare, set against the tenet of linguistics that all languages have an equal power of expression. These two ideas motivate the view that an asymmetric equivalence is typical, with multiple equivalent utterances in one language comparable to one utterance in another language, and vice versa. These asymmetrical equivalences cannot be expressed in terms of deep structure. This leads Kachru to remark, 'instead of waiting for theoretical linguists to come up with a more adequate notion of deep structure, contrastive analysts [need to] push towards a set of universal criteria to characterize equivalence' (Kachru 1975b: 3). Kachru then demonstrates the necessity of pragmatic over semantic and syntactic equivalence through a detailed analysis of causative constructions in English, Hindi, and Kannada. On the basis of examples, she identifies three semantic characteristics of causative constructions in English (incidental versus intended causation, agent control, and direct versus mediated causation), and proceeds to demonstrate five syntactic consequences of these, revolving around the semantics of particular causative verbs (cause, make, or have) and the impact this has on the syntax of the effect clause. She shows how these characteristics do not apply to causative constructions in Hindi and Kannada. The morphology and syntax of causative constructions permit effect clauses that are ruled out by the subcategorization of English causative verbs, while at the same time these constructions require different semantic restrictions on syntax. For example, agent control is not possible, by virtue of the morphologically derived causatives in South Asian languages. By this argument, with reference to this data set, there simply is no deep structure equivalence between causatives in English and causatives in South Asian languages. Kachru summarizes in the following quotation:

To the extent that the semantic facts are not the same, it is hard to imagine, at this stage, a universal base that would provide the necessary criteria for establishing equivalences of this kind. Notice that semantic notions such as control have important pragmatic consequences [the appropriateness of one example in Hindi-Urdu vs. inappropriateness of its equivalent in English]. Notice also that a semantic notion such as volition may result in a situation in which optimal equivalence in meaning is in conflict with optimal equivalence in terms of structure. The conclusion is unescapable that in order to establish cross-linguistic equivalences, serious research in the areas of what have come to be known as conversational postulates and pragmatics are as important as deep structures and transformational rules. (Kachru 1975b: 11-12)

Other publications, such as Kachru (1979c), articulate similar arguments applied to description rather than to the establishment and teaching of cross-linguistic equivalence. Kachru (1979c) demonstrates that a full description of the meaning of serial verb constructions in Hindi must take into account not only syntax and semantics, but also elements of pragmatic context, not least because:

[T]he total meaning of the serial verbal construction is not derivable from either the lexical meanings of the verbs involved or the meaning of the sentence in which the serial verb occurs. In getting the 'message' of sentences with serial verbs, the hearer or reader has to attempt to determine the stance of the speaker/author and deduce the meaning from other factors such as participants involved in the 
speech event, and their relationship to each other, as well as the purpose of the speaker/author in using the construction. This leads to the conclusion that an account of verb serialization, at least in Hindi-Urdu and other South Asian languages, needs a pragmatic in addition to a syntactic-semantic element. (Kachru 1979c: 166)

Kachru (1983a) extends this concern with pragmatics and culture to English language texts. Her purpose is to observe habitual ways of producing discourse in Indian English, and to discuss problems in interpretation that speakers of other varieties experience when they encounter these strategies. This observation begins with an account of clause formation and the status of subjects in Indic languages, with examples from Hindi. In other words, the account is anchored in empirical, descriptive grammar. Kachru goes on to examine cross-linguistic texts in English, tracing the discourse implications that these grammatical features have for authors trying to present their ideas in English. For example, 'Since English does not normally accommodate complexity in single clauses of the type that Indic languages allow for, Indian writers of English have to find a way of expressing what they perceive to be related events in single sentences. The coordinator and provides one such device for expressing relatedness' (Kachru 1983a: 63). The consequences of the multilingual author's production of a text, that is to say, the consequences of that author's choices and considered responses to influences and expectations, is a different grammar, 'What this discussion brings out is the fact that the grammar of Indian English is different in some respects from the grammar of native varieties of English.' The importance of this point cannot be overstated. Even as recently as the 1990s, there was a surprising degree of reticence in asserting grammatical differences between standardized or 'national' varieties of English, with the obvious exception of Braj Kachru's work (B. Kachru 1983; Davis 2006: 517). Yamuna Kachru adds the weight of her own research and academic judgment to Braj Kachru's position.

\section{CULTURE AND GRAMMAR}

Kachru's involvement in pragmatics research leads to repeated reformulation of her defining assumptions concerning culture and grammar. In Kachru (1992a) she adopts a definition of culture as 'shared knowledge' forming the basis of behavior and interpretation, and advances the view that this must of necessity be reflected in linguistic structure.

\footnotetext{
Culture can be defined as shared knowledge, i.e. what people 'must know in order to act as they do, make the things they make, and interpret their experience in the distinctive way they do' (Holland and Quinn 1987). The first part in this definition ('act as they do') refers to behavior in general, including verbal behavior; the second ('make the things they make') refers to artifacts; and the third ('interpret their experience') refers to the structure of knowledge. Both the first and the third parts are relevant to my purposes here, since linguistic structure necessarily reflects the structure of knowledge. (Kachru 1992a: 341)
}

Kachru grounds linguistic structure in culture, first, because verbal behavior is part of the behavior underpinned by shared knowledge, and second, because linguistic structure necessarily reflects the structure of that shared knowledge. This calls to mind the Chomskyan definition of language as tacit knowledge, but also the cultural and linguistic relativism of both American and European structuralism: the linguistic system is the means by which 
the world of meaning and experience is organized. Her goal in this chapter is to give a precise account of cultural differences between Indian English and American English, and to do this empirically and quantitatively. Between grammar and culture lies use, the characterization of which can be termed 'style.' By defining tokens of use in terms of grammatical and functional types intersecting with cultural categories, Kachru is able to enact a quantitative comparison of linguistic cultures and give an empirical basis to statements concerning language and culture, which may then contribute to an analysis of styles of English in India and America. Accordingly:

IE [Indian English] rhetorical style is characterized by high involvement as compared to the AE [American English] rhetorical style. This style is characterized by a higher frequency of occurrence of stance-marking adverbials in journalistic writing, and a difference in the use of evidentials and frequent use of person hopes and wishes in academic writing. [... The rhetorical style of IE thus reflects an attempt to create the Sanskritic noetics in English: it expresses the same cultural meaning as the Indian languages do. In this sense, English in India has truly become an Indian language. (Kachru 1992a: 347)

Kachru's exploration of the connections between culture, grammar and style provide a strand of research creativity that finds expression in a number of articles and books including Kachru (1983a, 1988b, 1988c, 1991b, 1994a, 1996c, 1997a, 1999; 2001b), Kachru and Nelson (2006f), and Kachru and Smith (2008b). Kachru (1999) pursues the question of cultural meaning and rhetorical style in a critique of contrastive rhetoric. She defines culture as 'the pattern of meanings embodied in symbolic forms, including actions, utterances, and meaningful objects of various kinds, by virtue of which individuals communicate with one another and share their experiences, conceptions and beliefs' (Kachru 1999: 77, citing Thompson 1990: 132). Language is subsumed under culture by this definition. As Kachru (1999: 77) states, 'That cultural considerations play a role in the development of linguistic structures and rhetorical patterns is corroborated from the history of writing in English in the Outer Circle.' This observation enables Kachru to delineate her critique of contrastive rhetoric. Briefly, in her view, the field of contrastive rhetoric is limited by the extent to which its proponents employ a deficit approach in analyzing literacy and discourse in the Outer and Expanding Circles. To the extent that practitioners engage in contrastive rhetoric to discover the 'meaning potential realized in texts' (Kachru 1999: 86) it is a legitimate activity.

Kachru and Smith (2008b) is a book-length treatment of cultures and world Englishes. The authors summarize the import of several definitions of culture as follows:

Although it is difficult to define precisely what is meant by the term 'culture,' what is clear from all the attempts defining it is that culture is both historic and immediate; it shapes action-verbal as well as a variety of other actions - and in turn is shaped by them. It is a dynamic process rather than a static, monolithic entity with a stable existence. (Kachru and Smith 2008b: 31)

This formulation of culture as a dynamic process is of critical importance within the world Englishes approach as founded by Braj Kachru. Note the use of the term acculturation and its designation as a process in the following quotation from their concluding chapter:

The spread of a natural human language across the countries and regions of the planet has resulted in variation as a consequence of nativization and acculturation of the language in various communities as 
has been discussed extensively in the linguistic literature. These processes have affected the grammatical structure and the use of language according to local needs and conventions. (Kachru and Smith 2008b: 177)

Grammar, though still a structure, is observed to change in response to the demands of local social and cultural context. Culture, as part of that context, is a process.

\section{FIRTHIAN/HALLIDAYAN LINGUISTICS}

At the very beginning of Kachru's academic career, she gained exposure to the work of J. R. Firth at the School of Oriental and African Studies, and an awareness of Firth's seminal teachings on the 'context of situation' illuminated much of her own academic research. Over time, the Firthian influence was deepened and extended by a period of long contact with the work of Michael Halliday, Ruqaiya Hassan and associates in the systemic-functional school of linguistics, with their emphasis on the semantic/pragmatic basis of language and a functional linguistic approach.

Kachru (1987b) is an important illustration of the growth of Yamuna Kachru's particular approach to grammar in this perspective. The aim of the paper is to demonstrate the interconnectedness of ergativity, subjecthood, and topicality in Hindi-Urdu. Here, the theoretical framework can be termed 'Hallidayan,' as this study draws explicitly on material identified in Halliday and Hasan (1976). The paper begins with a discussion of ergativity in Hindi, but then applies different strategies for analyzing cohesion derived from Halliday and Hasan (1976). The method for analyzing topicality developed by Talmy Givón (1983) is deployed to show that typologically Hindi-Urdu is 'mixed' with respect to ergativity.

Just as Halliday and Hasan's (1976) approach to cohesion informs Kachru's (1987b) work on typology and pragmatics, so does Halliday's (1973) 'context of culture' provide the basis of Kachru's (2006) integration of grammar and culture in bilingual creativity, and lead to recognition of a debt to systemic-functional linguistics:

\footnotetext{
The context of culture defines the potential, or the range of possibilities, and the context of situation determines the actual, or the choice that takes place (see Halliday 1973). This is true of linguistic structure as well as rhetorical patterns. Language is essentially an interrelated set of texts in which meaning potential is actualized: people express meanings to realize some social goal. This suggests that the notion of bilinguals' creativity in world Englishes paradigm is intimately related to the notion of meaning potential in systemic linguistics. (Kachru 2006b: 225)
}

In a later paper, which provides an overview of approaches and perspectives in world Englishes, the link to Hallidayan linguistics is made explicit in the discussion of 'nativization and acculturation,' which are seen to signify 'both systemic and structural changes in Hallidayan terms' (Kachru and Smith 2009: 3). In this study the analysis highlights the importance of 'volitionality' in determining the shape of relevant grammatical forms:

At the clause level, Indian English makes systematic choices in terms of volitionality, therefore, the following is perfectly grammatical: We went to a Thanksgiving party yesterday and I enjoyed very much. The mental state of how going to a party affects one is not a voluntary act; it is a non-volitional event, hence enjoy is non-volitional and does not have to be used as a transitive verb. Most transitive verbs usually signal volitional acts. This is true of like also; it is often used as an intransitive verb in Indian English, e.g., I hear what he is saying and I am not liking. (Kachru \& Smith 2009: 3) 
In the same paper, the applicability of a systemically-based approach to grammatical analysis is further evidenced through an account of the 'realis' versus 'irrealis' distinction in Indian English:

\begin{abstract}
In tense-aspect the choice is not between present, past, and future, and imperfect and perfect, but between realis and irrealis on the one hand and between imperfect, durative and perfect aspects on the other. Tense distinctions in terms of present, past, and future are also made, but they are secondary. This system of choices justifies characteristic uses such as you must be knowing her and I was not liking the movie, so we left early. All aspects participate in realis and irrealis constructions, therefore, all the following sentences are grammatical in Indian English: you must know him (imperfect), you must be knowing him (durative), and you must have known him (perfect). (Kachru \& Smith 2009: 3)
\end{abstract}

The quotation above serves to illustrate an important finding that emerged from a number of Kachru's studies of grammar and grammatical variation within and across languages. Essentially, much of Kachru's work in this field leads to an understanding of the interlinked dynamics of language, culture and linguistic variation. If, in Hallidayan terms the defining quality of language is the expression of meaning, an important aspect of world Englishes is the extent to which speech communities around the world express diverse cultural meanings. Thus Kachru concludes:

There is enough research to show that variation in lexicogrammar, discourse strategies, and literary styles results from the relevant speech communities attempting to express their own meanings in English [...] This is as true of the Outer and Expanding Circle varieties as it is of the Inner Circle Englishes such as American, Australian, Canadian, English, Irish, Scottish, and others. In all these contexts, cultural meanings that need to be expressed lead to linguistic creativity that exploits the meaning potential of the English language. (Kachru 2001b: 344)

\title{
CONCLUSION
}

Many themes can be seen in Yamuna Kachru's work as a linguist. One strand of continuity is a rigorous empiricism involving detailed understanding of different areas of linguistic theory, and the relationship that these theories have to the complexities of descriptive grammar in English and the languages of South Asia. Paradoxically, another strand of continuity is the flexibility which enabled Kachru to pursue the description of her object of study even as she discovered the limitations of various theories to account for it. The result of this bringing together of empiricism and flexibility is a gradual redefinition of grammar. Grammar begins for Kachru as a mentalist generative system, describable in its own terms and thus permitting the analysis of Hindi syntax in its own terms. Eventually, generative grammar could no longer satisfy Kachru's empirical standard. The increasingly contentious debate over the role of semantics in generativism, and the typological difficulties involved in hypothesizing universals of languages brought about the divergence of generative approaches, and combined with the emergence of sociolinguistics, led Kachru to search for a more concrete and text-based form of grammatical evidence, grammatical description, and grammatical definition. Informed by the approaches of Firth and Halliday, and by theories of language use, Kachru came to redefine grammar as a dynamic function of culture and the context of situation. 
In one of her most recent papers, Kachru (2008f: 3) explores the issue of grammar and point of view. She does not cite Saussure, but instead gives a straightforward example of the linguistic description of relative clauses versus prepositional phrases, pointing out that attention given to relative clauses, because they lend themselves to linguistic description, far outweighs that given to prepositional phrases with a comparable and arguably more widespread or common usage. Her point was to encourage further thought and research on an important aspect of language use, not to bemoan the way in which the successes of linguistics have a way of entrapping our thoughts within a blinkered point of view. I do think that her steady and persistently pragmatic empiricism points to a way out of the house of mirrors that linguistics can become. There is perhaps no fitting place to conclude, than with a story that Yamuna Kachru told of her days in London (personal communication). As a graduate student, she went to see Firth and mentioned that she had received quite a lot of criticism from various colleagues for adopting a generative approach to Hindi syntax. Firth told her, 'Yamuna, you have to do your analysis in your own way.' Reviewing the milestones of a lifetime's research, it is safe to say that she did just that, and in so doing advanced our understanding of Hindi, of English, of grammar, and of culture.

\section{REFERENCES}

[All references to Yamuna Kachru's work appear in the bibliography at the end of this special issue.].

Chomsky, Noam. 1957. Syntactic structures (Janua Linguarum 4). The Hague: Mouton.

Chomsky, Noam. 1965. Aspects of the theory of syntax. Cambridge, MA: MIT Press.

Davis, Daniel R. 2006. World Englishes and descriptive grammars. In Braj B. Kachru, Yamuna Kachru, and Cecil L. Nelson (eds.), The handbook of world Englishes, 509-525. Malden, MA: Blackwell.

Givón, Talmy (ed.). 1983. Topic continuity in discourse: A quantitative cross-language study (Typological Studies in Language 3) Amsterdam: John Benjamins.

Halliday, Michael Alexander Kirkwood. 1973. Explorations in the functions of language. London: Edward Arnold.

Halliday, Michael Alexander Kirkwood, \& Ruqaiya Hasan. 1976. Cohesion in English. London: Longman.

Kachru, Braj B. 1983. The Indianization of English: The English language in India. Delhi: Oxford University Press.

Schmidt, Ruth L. 1969. A structural analysis of modern Hyderabadi Dakhini Urdu. Philadelphia, PA: University of Pennsylvania dissertation.

Thompson, John B. 1990. Ideology and modern culture: Critical social theory in the era of mass communication. Stanford, CA: Stanford University Press.

(Received 1 November 2014) 